\title{
Aid fund faces cash crunch
}

Does the Global Fund to Fight AIDS, Tuberculosis and Malaria risk becoming a victim of its own success? With demand for its programmes outstripping donor contributions, the fund will convene an informal retreat of board members next week to address a potential cash crisis.

Unless sufficient extra money can be raised, the eight-year-old fund may be forced for the first time to reject otherwise-solid new proposals from recipient countries, and trim others.

The fund, based in Geneva, Switzerland, accounts for a quarter of all international financing to fight AIDS, two-thirds of that for tuberculosis, and three-quarters of that for malaria. It estimates that it has saved some 4.9 million lives through the US $\$ 18.7$ billion it has spent on supporting health in 140 countries - including putting 2.5 million HIV-infected people on antiretroviral drugs, treating 6 million people with drugs against tuberculosis, and distributing 104 million bednets to prevent malaria.

In part, the fund has spurred the very demand that now threatens to drain it. Five years ago, many countries lacked the expertise to design and implement multimillion-dollar health projects, says Bernard Rivers, head of Aidspan, a watchdog group in Nairobi, Kenya, that monitors the Global Fund. Now, he says, "the fund has more sound, solid and implementable proposals coming in, which is very good news".

Donations have also grown steadily: funding rounds for 2008 and 2009 were the largest ever, with $\$ 3.3$ billion pledged in 2009, double that in 2005. Still, the agency has had problems meeting existing commitments and funding new rounds of programmes. At its last board meeting, in Addis Ababa, Ethiopia, in November 2009, the fund was forced to cut spending on all new projects approved there.

The upcoming retreat, to be held in Marseille, France, on 1-3 February, will not yield any formal decisions. But it will set the tone for two crucial 'replenishment' meetings this year, in March and October, at which donors will announce their new commitments to the fund.

Christoph Benn, director of the fund's external relations and partnerships, says he is optimistic that donors will keep up their support despite the global economic crisis. He points out that the United States, the fund's top donor, announced in December that it intends to slightly increase its contribution.

Rivers agrees, saying that, at worst, donors will be "flatlining" budgets. But even that might mean an end to the fund's tradition of financing all projects judged as technically and organizationally sound by its Technical Review Panel, he says.

Sharonann Lynch, an HIV/AIDS policy adviser at Médecins Sans Frontières in New York City, says that some donors, including several European countries, may press to scale back the fund and refocus it on the poorest countries with the highest burden of disease. She says that that would be "a large backward step" for HIV programmes.

Moreover, the other global powerhouse spender in the area - the US President's Emergency Plan for AIDS Relief - is experiencing flat spending. Benn agrees that projects might have to be prioritized on the basis of the wealth and degree of disease burden in recipient countries. "What you will see is a discussion where some board members might say that in the future we need to rethink whether we can fund every possible proposal coming to the board, but there will also be many board members defending exactly that," he says. "What the outcome will be is not very clear." Only one-third of board votes belong to donors; recipient countries and civil-society members also have voting power.

The financial crisis should not be used as an excuse for tightening belts, says Benn, arguing that it is the poorer countries that bear the brunt of the recession.

Declan Butler

\section{Correction}

The Editorial 'Self-inflicted damage' (Nature 463,$270 ; 2010$ ) incorrectly stated that Rita LeviMontalcini intends to appoint a new commissioner at the European Brain Research Institute in Rome. In fact, if her plans go ahead, the appointment would be made by the local prefecture. In addition, the Editorial spoke of Italy's "none-too-good scientific image". This was meant to refer to the nation's image problem in terms of reliability as a scientific partner; it was not intended to call into question Italy's scientific skills and ability. 